\title{
Prevalence of Atypical Disorders and Associated Factors in Under- graduate Students of Prince of Songkla University, Songkhla, Thailand
}

\author{
Orapan Fumaneeshoat, M.D.
}

Family Medicine and Preventive Medicine, Faculty of Medicine, Prince of Songkla University, Hat Yai, Songkhla 90110 Thailand. Received 24 December 2018 • Revised 21 February 2019 • Accepted 4 March 2019 • Published online 11 April 2019

\section{Abstract:}

Objective: To quantify the prevalence of eating disorders and factors associated with eating disorders among undergraduate students in Prince of Songkla University, Hat Yai Campus.

Material and Methods: This study was a cross sectional descriptive study using random sampling by proportionate accidental sampling. We used the Thai Eating Attitudes Test-26 (EAT-26) for collecting information about eating attitudes. Participants who had scores equal or higher than $12(\geq 12)$ were assumed to have atypical eating attitudes and behaviors. We used the $\mathrm{R}$ and $\mathrm{R}$ studio program to analyze information. Multivariate logistic regression was used for correlation analysis.

Results: In this study, we had completed questionnaires from 500 students (response rate 65.6\%). The overall prevalence of atypical eating attitudes and behaviors in undergraduate students in Prince of Songkla University, Hat Yai Campus was $37.2 \%$. We found that overweight body mass index (BMI) (BMI $\left.23.00-24.99 \mathrm{~kg} / \mathrm{m}^{2}\right)$ and obesity BMl ( $\geq 25.00 \mathrm{~kg} /$ $\mathrm{m}^{2}$ ) were significantly more prevalent in students with atypical eating attitudes and behaviors than normal BMI (18.50$\left.22.99 \mathrm{~kg} / \mathrm{m}^{2}\right)$, with odds ratios of 3.3 [95\% confidence interval $\left.(\mathrm{Cl})=1.8-6.2\right]$ and $3.7(95 \% \mathrm{Cl}=1.9-6.9)$, respectively. However, multivariate logistic regression revealed no associations between atypical eating attitudes and behaviors, sex, target weight, biological disease, psychological disease, current medication(s) or faculty. Atypical eating attitudes and behaviors were significantly associated only with body mass index BMl. The overweight and obese BMI groups had significantly increased risks of 3.3 and 3.7 times of atypical eating attitudes and behaviors compared to the normal group, with $95 \%$ Cls of $1.8-6.2$ and $1.9-6.9$, respectively.

Conclusion: From this study, overweight BMI and obesity BMI were significantly more prevalent in students with atypical eating attitudes and behaviors than normal BMI. BMI was the only factor significantly associated with atypical eating attitudes and behaviors.

Keywords: BMI, eating attitudes, eating behaviors, undergraduate students

Contact: Orapan Fumaneeshoat, M.D.

Family Medicine and Preventive Medicine, Faculty of Medicine, Prince of Songkla University, Hat Yai, Songkhla 90110 Thailand.

Email: orfp_1187@hotmail.com
J Health Sci Med Res 2019;37(2):121-131 doi: 10.31584/jhsmr.201947 www.jhsmr.org 


\section{Introduction}

Eating disorders (EDs) refers to a group of abnormal eating behaviors involving either insufficient or excessive food intake. Anorexia nervosa, bulimia nervosa and binge eating are considered to be the most common eating disorders. ${ }^{1}$ Patients with these disorders predominately show a preoccupation with body weight, shape and diet. Eating disorders also frequently occur with other psychiatric disorders such as major depressive disorder, bipolar disorder, substance abuse and anxiety disorder. ${ }^{2}$

People with anorexia have an extreme fear of gaining weight, which propels them to maintain a weight far less than normal. Bulimia is characterized by a cycle of binge eating, followed by attempts to remove unwanted calories. People with binge eating disorders often eat an uncontrollable, large amount of food during the binges. ${ }^{2}$

The cause of eating disorders is currently unknown. However, many studies have suggested that eating disorders involve a combination of biological, psychological and environmental abnormalities. A common phrase in such conditions is that "Genetics loads the gun, environment pulls the trigger". ${ }^{3}$

Many studies have found many complications associated with eating disorders, including a high mortality rate. A review of eating disorder complications in the American Journal of Medicine in 2016 discussed the medical complications associated with the weight loss and malnutrition of anorexia nervosa, as well as from the purging behaviors that characterize bulimia nervosa. ${ }^{4}$

Various studies have reported on the prevalence of eating disorders. Asia and The Pacific in 2016 reported eating disorder prevalences in Southeast Asia of $10.3 \%$ in Singapore, $18.5 \%$ in Malaysia, $48.8 \%$ in Vietnam and a very low prevalence in Thailand. ${ }^{5} \mathrm{~A}$ recent report of prevalence of eating disorders in Thai college students found the prevalences of anorexia nervosa and bulimia nervosa were $0.5 \%$ and 1.0 to $3.0 \%$, respectively. ${ }^{6}$ Another study done in medical students in Prince of Songkla
University (PSU), Hat Yai Campus found 15.9\% showed signs of atypical eating attitudes and behaviors. ${ }^{7}$

The reported prevalences of the eating disorders in college students were controversial. In addition, previous studies have reported only the prevalences of eating disorders, however, none of them examined associated factors. Therefore, our study quantified the prevalence of eating disorders in PSU student in Hat Yai Campus from July to August, 2017 and examined the associated factors.

\section{Material and Methods}

This study was a descriptive, cross-sectional study. The participants were undergraduate students from the 16 faculties in PSU, Hat Yai Campus, Thailand. The full population was 15,548 students $(n=15,548)$. We set an allowable error of $5.0 \%$, after using these numbers with the Taro Yamane formula, the required sample size was 390 students. The expected response rate was $50.0 \%$ so the proposed numbers of samples was doubled to 780 students. The participants were selected based on the proportional to size basis, stratifying by sex and faculty based on the student statistics in year 2016 . The sampling technic is convenient sampling until the numbers of sample reach the calculated sample size for each faculty and by sex. The participants were provided with a participant information form, in order to review and consider participation. An informed consent was signed later if the participants agreed to participate in the research. After finishing the self-administered questionnaire, the participants returned their questionnaire in an opaque box for confidentiality purposes. The body mass index (BMI) of participants was classified using the Asian BMI cut-off points.

\section{Questionnaire}

In 1982, the Eating Attitudes Test ${ }^{* \star *}($ EAT -26 *Thai* version) was adapted from the Eating Attitudes Test-40 (EAT-40), used for examining eating disorders in 
a general population. ${ }^{8}$ The EAT-26 included questions on dieting, bulimia, food preoccupation and oral control. ${ }^{9}$ In 2013, Kaewpornsawan et al. ${ }^{10}$ translated the EAT-26 into Thai version. The Thai version was tested in pregnant women, known to have various eating behaviors related to the pregnancy. The mean score of the EAT-26 in pregnant women with eating disorders was 30.4 [standard deviation (S.D.)=15.7] and 6.5 (S.D.=5.9) in pregnant women with non-eating disorders. ${ }^{10}$ From the analysis of Kaewpornsawan, the appropriate cut-off score of the EAT-26 should be at 12 with $71.4 \%$ sensitivity, $94.3 \%$ specificity, 11.83 positive likelihood ratio and 0.31 negative likelihood ratio. Therefore, we decided to use the EAT-26 as the questionnaire to quantify the prevalence of eating disorders in the PSU college students. We did a pilot study for reliability testing of the questionnaire in undergraduate students in a nearby university in southern Thailand and the Cronbach's alpha coefficient was 0.701

The EAT-26 Thai version is divided into 3 parts as follows:

Part 1: General demographics (sex, birth, height, weight, targeted body weight, underlying diseases, current medications).

Part 2: 26 questions about health and eating behavior characteristics.

Part 3: 5 questions about eating behaviors during the previous 6 months.

The self-administered questionnaire takes around 15-30 minutes to complete.

\section{Data management}

Microsoft Excel version 2013 was used for data recording. The data were statistically analyzed using the $\mathrm{R}$ and $\mathrm{R}$ studio program. Frequency, percentage, average and standard deviation were used if the data had normal distribution. Median and interquartile range were used if the data did not have normal distribution.
The central values of targeted body weight and current body weight were analyzed using Paired T-test to show arithmetic mean differences and standard deviations if the data had normal distribution, while the Wilcoxon's signed rank test was used to show median differences and interquartile ranges for data which did not have normal distribution.

Atypical eating attitudes and behaviors and associated factors such as sex, faculty, body mass index (BMI), targeted body weight, biological disease, psychological diseases and current medications were analyzed by multivariate logistic regression, with odds ratios for measuring associations and Wald $p$-value for significance.

\section{Results}

This study was conducted using the Thai version of the EAT-26 questionnaire in a total of 780 PSU, Hat Yai Campus students. Five hundred students completely answered all questions, giving a response rate of $65.6 \%$.

\section{Part 1: Demographic data}

Of the 500 individuals who completed the questionnaire, 324 were female $(64.8 \%)$ and 176 were male $(35.2 \%)$. The most common age group was 18-22 years (90.6\%), with a median age of 20 years, interquartile range (IQR 2). Most of the participants were under 57 $\mathrm{kg}(53.0 \%)$. The median weight was $56 \mathrm{~kg}$ (IQR 17). The most common height group was $154-167 \mathrm{~cm}$ (56.4\%). The median height was $163 \mathrm{~cm}$ (IQR 12). The most common BMl group was normal weight (BMI 18.50-22.99 kg/m², $51.2 \%$ ). The median BMI was $20.57 \mathrm{~kg} / \mathrm{m}^{2}$ (IQR 5.6). However, most of the students $(64.0 \%)$ had a target body weight lower than $57 \mathrm{~kg}$. The median target weight was $52 \mathrm{~kg}$ (IQR 13). Most participants did not have an underlying biological or psychological disease or use a current medication (84.0, 99.2, and 95.4\%, respectively) (Table 1). 
The highest number from any one faculty was from the Faculty of Management Science (15.8\%), followed by the Faculty of Science (14.2\%), while the smallest number of participants was from the Faculty of Veterinary Science $(0.6 \%)$ (Table 2$)$.

Table 1 Demographic characteristics of the respondents $(n=500)$

\begin{tabular}{|c|c|}
\hline Characteristic & Number $(\%)$ \\
\hline \multicolumn{2}{|l|}{ Sex } \\
\hline Male & $176(35.2)$ \\
\hline Female & $324(64.8)$ \\
\hline \multicolumn{2}{|l|}{ Age (years) } \\
\hline$<18$ & $3(0.6)$ \\
\hline $18-22$ & $453(90.6)$ \\
\hline$>22$ & $44(8.8)$ \\
\hline Median & 20 \\
\hline IQR & 2 \\
\hline \multicolumn{2}{|l|}{ BMI $\left(\mathrm{kg} / \mathrm{m}^{2}\right)$} \\
\hline <18.50 (underweight) & $108(21.6)$ \\
\hline 18.50-22.99 (normal) & $256(51.2)$ \\
\hline 23.00-24.99 (overweight) & $59(11.8)$ \\
\hline$\geq 25.00$ (obese) & $77(15.4)$ \\
\hline Median & 20.57 \\
\hline IQR & 5.6 \\
\hline \multicolumn{2}{|l|}{ Weight (kg) } \\
\hline$<57$ & $265(53.0)$ \\
\hline $57-76$ & $180(36.0)$ \\
\hline$>76$ & $55(11.0)$ \\
\hline Median & 56 \\
\hline IQR & 17 \\
\hline \multicolumn{2}{|l|}{ Height (cm) } \\
\hline$<154$ & $41(8.2)$ \\
\hline $154-167$ & $282(56.4)$ \\
\hline $168-181$ & $161(32.2)$ \\
\hline$>181$ & $16(3.2)$ \\
\hline Median & 163 \\
\hline IQR & 12 \\
\hline
\end{tabular}

Table 1 (continued)

\begin{tabular}{ll}
\hline Characteristic & Number (\%) \\
\hline $\begin{array}{l}\text { Underlying diseases } \\
\text { Biological* } \\
\text { Yes }\end{array}$ & \\
No & $80(16.0)$ \\
Psychological ${ }^{*}$ & $420(84.0)$ \\
Yes & \\
No & $4(0.8)$ \\
Current medication(s) & $496(99.2)$ \\
Yes & \\
No & $23(4.6)$ \\
\hline
\end{tabular}

*For biological diseases and psychological diseases, the questions included any biological or psychological diseases.

$\mathrm{BMI}=$ body mass index, IQR=interquartile range

Table 2 Number of participants from each Prince of Songkla University faculty $(n=500)$

\begin{tabular}{ll}
\hline Faculty & Number (\%) \\
\hline Thai Traditional Medicine & $17(3.4)$ \\
Natural Resources & $38(7.6)$ \\
Dentistry & $17(3.4)$ \\
Medical Technology & $13(2.6)$ \\
Law & $28(5.6)$ \\
Nursing & $24(4.8)$ \\
Medicine & $49(9.8)$ \\
Pharmaceutical Science & $21(4.2)$ \\
Management Science & $79(15.8)$ \\
Science & $71(14.2)$ \\
Engineering & $64(12.8)$ \\
Liberal Arts & $30(6.0)$ \\
Economics & $20(4.0)$ \\
Veterinarian Science & $3(0.6)$ \\
Agro-industry & $18(3.6)$ \\
International College & $8(1.6)$ \\
\hline
\end{tabular}




\section{Part 2: Results of the EAT-26 questionnaire}

From a total of 500 individuals who completed the EAT-26 questionnaire, 186 (37.2\%) individuals had an EAT-26 score of 12 or higher, indicating that the prevalence of atypical eating attitudes and behaviors of PSU, Hat Yai Campus students was $37.2 \%$.

Sixty-three males (12.6\%) and 123 (24.6\%) females had an EAT-26 score of 12 or higher (signifying atypical eating attitudes and behaviors). In addition, $51.2 \%$ of the students had a BMl $18.50-22.99 \mathrm{~kg} / \mathrm{m}^{2}$, whereas $15.4 \%$ of the students had a BMI at $\geq 25.00 \mathrm{~kg} / \mathrm{m}^{2}$. However, the most common body weight goal was $<57 \mathrm{~kg}$ reported by $53.0 \%$ of the students. The second most common target body weight was $57-76 \mathrm{~kg}$ reported by $12.2 \%$ of the students. Regarding the results of the EAT-26, 420 (84.0\%) students reported no biological disease, 496 (99.2\%) reported no psychological disease, and 477 (95.4\%) were taking no current medication (Table 3).
Multivariate logistic regression revealed no associations between atypical eating attitudes and behaviors, sex, target weight, biological disease, psychological disease, current medication and faculty (Table 4).

Atypical eating attitudes and behaviors were significantly associated only with BMI. The overweight and obese BMI groups were significantly associated with 3.3 and 3.7 times increasing odds of having atypical eating attitudes and behaviors compared to the normal weight group, with $95 \%$ Cls of $1.8-6.2$ and 1.9-6.9, respectively (Figure 1).

Thus, most respondents scored at least 1 on each item and thus had atypical eating attitudes and behaviors. Seventy-six (40.9\%) individuals responded to item\#12 "Think about burning up calories when I exercise". The second most common was 67 (36.0\%) responded item no. 3 "Find myself preoccupied with food", whilst only 10 $(5.4 \%)$ individuals gave a positive respond to question no. 9, "Vomit after I have eaten" (Table 5).

Table 3 Associations between demographic characteristics, faculties and Eating Attitudes Test-26 scores ( $n=500)$

\begin{tabular}{|c|c|c|c|c|}
\hline \multirow[b]{2}{*}{ Factor } & \multicolumn{2}{|c|}{ EAT-26 } & \multirow[b]{2}{*}{ OR $(95 \% \mathrm{Cl})$} & \multirow{2}{*}{$\begin{array}{l}\text { Wald } \\
\text { p-value }\end{array}$} \\
\hline & $\begin{array}{l}\text { Number of scores } \\
<12(\%)\end{array}$ & $\begin{array}{l}\text { Number of scores } \\
\geq 12(\%)\end{array}$ & & \\
\hline \multicolumn{5}{|l|}{ Sex } \\
\hline Male & $113(22.6)$ & $63(12.6)$ & 1.0 & \\
\hline Female & $201(40.2)$ & $123(24.6)$ & $1.1(0.6-2.1)$ & 0.674 \\
\hline \multicolumn{5}{|l|}{ BMI $\left(\mathrm{kg} / \mathrm{m}^{2}\right)$} \\
\hline$<18.50$ (underweight) & $82(16.4)$ & $26(5.2)$ & $0.6(0.4-1.0)$ & 0.075 \\
\hline 18.50-22.99 (normal) & $176(35.2)$ & $80(16.0)$ & 1.0 & \\
\hline 23.00-24.99 (overweight) & $25(5.0)$ & $34(6.8)$ & $3.3(1.8-6.2)$ & $0.002^{\star \star}$ \\
\hline$\geq 25.00$ (obese) & $31(6.2)$ & $46(9.2)$ & $3.7(1.9-6.9)$ & $<0.001^{\star *}$ \\
\hline \multicolumn{5}{|l|}{ Target weight (kg) } \\
\hline$<57$ & $205(41.0)$ & $115(23.0)$ & 1.0 & \\
\hline $57-76$ & $106(21.2)$ & $61(12.2)$ & $0.6(0.3-1.1)$ & 0.116 \\
\hline$>76$ & $3(0.6)$ & $10(2.0)$ & $1.6(0.3-7.4)$ & 0.566 \\
\hline
\end{tabular}


Table 3 Associations between demographic characteristics, faculties and Eating Attitudes Test-26 scores $(n=500)$

\begin{tabular}{|c|c|c|c|c|}
\hline \multirow[b]{2}{*}{ Factor } & \multicolumn{2}{|c|}{ EAT-26 } & \multirow[b]{2}{*}{ OR $(95 \% \mathrm{Cl})$} & \multirow{2}{*}{$\begin{array}{l}\text { Wald } \\
\text { p-value }\end{array}$} \\
\hline & $\begin{array}{l}\text { Number of scores } \\
<12(\%)\end{array}$ & $\begin{array}{l}\text { Number of scores } \\
\geq 12(\%)\end{array}$ & & \\
\hline \multicolumn{5}{|l|}{ Biological disease } \\
\hline No & $262(52.4)$ & $158(31.6)$ & 1.0 & \\
\hline Yes & $52(10.4)$ & $28(5.6)$ & $0.8(0.4-1.4)$ & 0.491 \\
\hline \multicolumn{5}{|l|}{ Psychological disease } \\
\hline No & $312(62.4)$ & $184(36.8)$ & 1.0 & \\
\hline Yes & $2(0.4)$ & $2(0.4)$ & $1.5(0.2-14.0)$ & 0.677 \\
\hline \multicolumn{5}{|l|}{ Current Medication } \\
\hline No & $303(60.6)$ & $98(34.8)$ & 1.0 & \\
\hline Yes & $11(2.2)$ & $12(2.4)$ & $1.6(0.6-4.2)$ & 0.386 \\
\hline \multicolumn{5}{|l|}{ Faculty } \\
\hline Thai Traditional Medicine & $10(2.0)$ & $7(1.4)$ & 1.0 & \\
\hline Natural Resources & $22(4.4)$ & $16(3.2)$ & $0.9(0.2-3.0)$ & 0.818 \\
\hline Dentistry & $11(2.2)$ & $6(1.2)$ & $0.7(0.2-3.0)$ & 0.602 \\
\hline Medical Technology & $7(1.4)$ & $6(0.6)$ & $0.9(0.2-4.3)$ & 0.907 \\
\hline Law & $18(3.6)$ & $10(2.0)$ & $0.6(0.2-2.4)$ & 0.505 \\
\hline Nursing & $15(3.0)$ & $9(1.8)$ & $0.9(0.2-3.4)$ & 0.889 \\
\hline Medicine & $33(6.6)$ & $16(3.2)$ & $0.8(0.2-2.6)$ & 0.658 \\
\hline Pharmaceutical Science & $13(2.6)$ & $8(1.6)$ & $0.9(0.2-3.4)$ & 0.853 \\
\hline Management Science & $49(9.8)$ & $30(5.0)$ & $0.8(0.3-2.5)$ & 0.728 \\
\hline Science & $49(9.8)$ & $22(4.4)$ & $0.6(0.2-2.0)$ & 0.426 \\
\hline Engineering & $44(8.8)$ & $20(4.0)$ & $0.7(0.2-2.2)$ & 0.520 \\
\hline Liberal arts & $16(3.2)$ & $14(2.8)$ & $1.2(0.3-4.2)$ & 0.793 \\
\hline Economics & $13(2.6)$ & $7(1.4)$ & $0.7(0.2-2.9)$ & 0.626 \\
\hline Veterinary Science & $2(0.4)$ & $1(0.2)$ & $0.5(0.0-7.0)$ & 0.582 \\
\hline Agro-industry & $8(1.6)$ & $10(2.0)$ & $1.4(0.4-6.0)$ & 0.615 \\
\hline International College & $4(0.8)$ & $4(0.8)$ & $1.4(0.2-8.7)$ & 0.729 \\
\hline
\end{tabular}

${ }^{*}$ Multivariate logistic regression analysis ${ }^{* *}$ significant at $p$-value $<0.05$

EAT=Eating Attitudes Test, OR=odd ratio, BMl=body mass index 
Table 4 Associations between demographic characteristics, faculties and Eating Attitudes Test-26 scores ( $n=500)$

\begin{tabular}{|c|c|c|c|c|}
\hline \multirow[b]{2}{*}{ Factors } & \multicolumn{2}{|c|}{ EAT-26 } & \multirow[b]{2}{*}{ OR $(95 \% \mathrm{Cl})$} & \multirow{2}{*}{$\begin{array}{l}\text { Wald } \\
\text { p-value* }\end{array}$} \\
\hline & $\begin{array}{l}\text { Number of scores } \\
<12(\%)\end{array}$ & $\begin{array}{l}\text { Number of scores } \\
\geq 12(\%)\end{array}$ & & \\
\hline \multicolumn{5}{|l|}{ Sex } \\
\hline Male & $113(22.6)$ & $63(12.6)$ & 1.0 & \\
\hline Female & $201(40.2)$ & $123(24.6)$ & $1.1(0.6-2.1)$ & 0.674 \\
\hline \multicolumn{5}{|l|}{ BMI $\left(\mathrm{kg} / \mathrm{m}^{2}\right)$} \\
\hline <18.50 (underweight) & $82(16.4)$ & $26(5.2)$ & $0.6(0.4-1.1)$ & 0.075 \\
\hline 18.50-22.99 (normal) & $176(35.2)$ & $80(16.0)$ & 1.0 & \\
\hline 23.00-24.99 (overweight) & $25(5.0)$ & $34(6.8)$ & $3.3(1.8-6.2)$ & $0.002^{* *}$ \\
\hline$\geq 25.00$ (obese) & $31(6.2)$ & $46(9.2)$ & $3.7(1.9-6.9)$ & $<0.001^{\star *}$ \\
\hline \multicolumn{5}{|l|}{ Target weight $(\mathrm{kg})$} \\
\hline$<57$ & $205(41.0)$ & $115(23.0)$ & 1.0 & \\
\hline $57-76$ & $106(21.2)$ & $61(12.2)$ & $0.6(0.3-1.1)$ & 0.116 \\
\hline$>76$ & $3(0.6)$ & $10(2.0)$ & $1.6(0.3-7.4)$ & 0.566 \\
\hline \multicolumn{5}{|l|}{ Biological disease } \\
\hline No & $262(52.4)$ & $158(31.6)$ & 1.0 & \\
\hline Yes & $52(10.4)$ & $28(5.6)$ & $0.8(0.5-1.4)$ & 0.491 \\
\hline \multicolumn{5}{|l|}{ Psychological disease } \\
\hline No & $312(62.4)$ & $184(36.8)$ & 1.0 & \\
\hline Yes & $2(0.4)$ & $2(0.4)$ & $1.5(0.2-14.0)$ & 0.677 \\
\hline \multicolumn{5}{|l|}{ Current Medication } \\
\hline No & $303(60.6)$ & $98(34.8)$ & 1.0 & \\
\hline Yes & $11(2.2)$ & $12(2.4)$ & $1.6(0.6-4.2)$ & 0.386 \\
\hline \multicolumn{5}{|l|}{ Faculty } \\
\hline Thai Traditional Medicine & $10(2.0)$ & $7(1.4)$ & 1.0 & \\
\hline Natural Resources & $22(4.4)$ & $16(3.2)$ & $0.9(0.2-3.0)$ & 0.818 \\
\hline Dentistry & $11(2.2)$ & $6(1.2)$ & $0.7(0.2-3.0)$ & 0.602 \\
\hline Medical Technology & $7(1.4)$ & $6(0.6)$ & $0.9(0.2-4.3)$ & 0.907 \\
\hline Law & $18(3.6)$ & $10(2.0)$ & $0.6(0.2-2.4)$ & 0.505 \\
\hline Nursing & $15(3.0)$ & $9(1.8)$ & $0.9(0.2-3.4)$ & 0.889 \\
\hline Medicine & $33(6.6)$ & $16(3.2)$ & $0.8(0.2-2.6)$ & 0.658 \\
\hline Pharmaceutical Science & $13(2.6)$ & $8(1.6)$ & $0.9(0.2-3.4)$ & 0.853 \\
\hline Management Science & $49(9.8)$ & $30(5.0)$ & $0.8(0.3-2.5)$ & 0.728 \\
\hline Science & $49(9.8)$ & $22(4.4)$ & $0.6(0.2-2.0)$ & 0.426 \\
\hline Engineering & $44(8.8)$ & $20(4.0)$ & $0.7(0.2-2.2)$ & 0.520 \\
\hline Liberal Arts & $16(3.2)$ & $14(2.8)$ & $1.2(0.3-4.2)$ & 0.793 \\
\hline Economics & $13(2.6)$ & $7(1.4)$ & $0.7(0.2-2.9)$ & 0.626 \\
\hline Veterinary Science & $2(0.4)$ & $1(0.2)$ & $0.5(0.0-7.0)$ & 0.582 \\
\hline Agro-industry & $8(1.6)$ & $10(2.0)$ & $1.4(0.4-6.0)$ & 0.615 \\
\hline International College & $4(0.8)$ & $4(0.8)$ & $1.4(0.2-8.7)$ & 0.729 \\
\hline
\end{tabular}

EAT=Eating Attitudes Test, OR=odd ratio, BMI=body mass index 


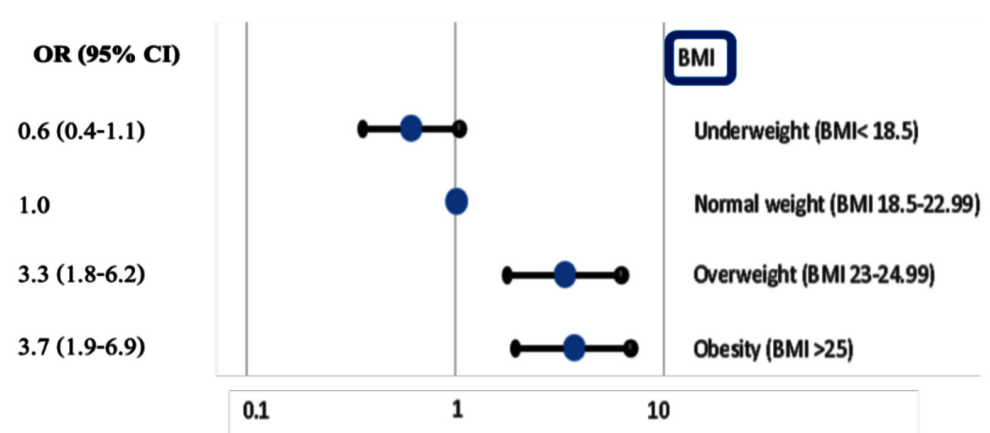

Figure $1 \mathrm{~A}$ forest plot showing the associations between body mass index and atypical eating attitudes and behaviors

Table 5 The responses and numbers of the students to the 26 individual questions of Eating Attitudes Test-26 part II

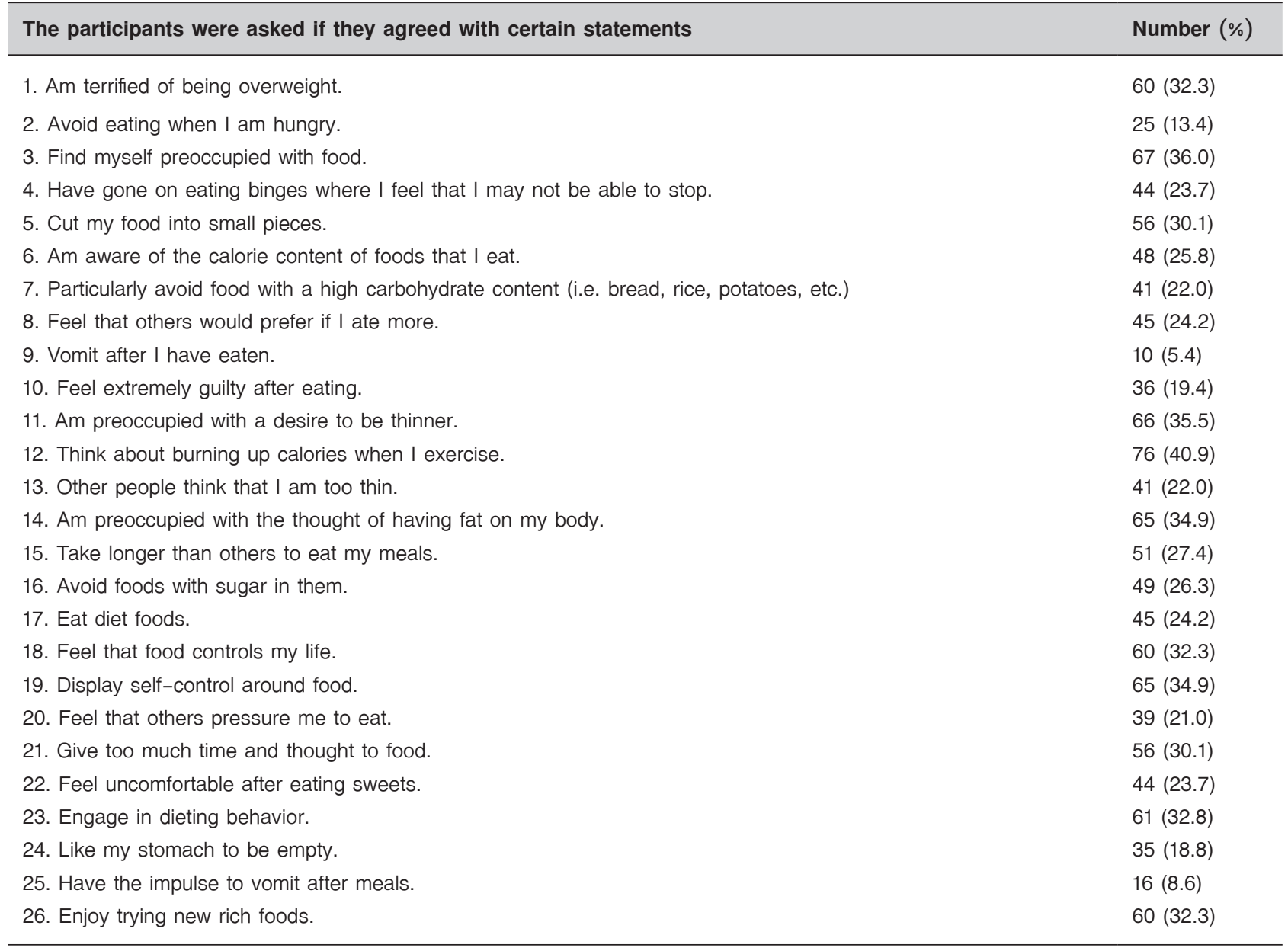

*For all items except no. 26, each of the responses could be answered using a 4-point scale with the following values: always $=3$, usually $=2$, often $=1$, sometimes, rarely or never $=0$. For item no. 26 , the responses were always, usually and often=0, sometimes $=1$, rarely=2, and never $=3$. 


\section{Discussion}

This study found a prevalence $37.2 \%$ of atypical eating attitudes and behaviors in university students, which was higher than in other similar studies. Although our study used $\geq 12$ as a cut-off-point, which was lower than in most other studies, this cut off point was verified for accuracy. It was a realistic and accurate cutoff point according to Thitawee's research in $2013 .{ }^{10}$ Other studies such as Areemit and Patjanasoontorn ${ }^{11}, 2012$ in undergraduate students from KhonKaen University and in 2013 Pattanathaburt et al. ${ }^{12}$ from Naresaun University used 20 as a cutoff point, and found abnormal eating behaviours of $3.0 \%$ and $6.3 \%$, respectively. A study by Pitanupong and Jatchavala ${ }^{7}, 2017$ of medical students in PSU, Hat Yai Campus used 12.5 as a cut off point showed $15.9 \%$ atypical eating attitudes. Hence the cut-off [no hyphen] point affects prevalence.

In the present, there are many articles on the worldwide social media about desirable body shapes which affect eating behaviors. In 2016, a study by Winijjakul ${ }^{13}$ suggested that in the past, atypical eating behaviors were limited to certain groups. But in modern times, social media is widespread, so people share data and pictures about nutrition very widely. However, the shared data is often not completely correct, so it can lead to misunderstandings about eating, but with social media such false data can spread worldwide. Hence, the prevalence of eating disorders in the present is higher than in the past. Furthermore, the Thai health report of 2014 showed that $34.2 \%$ of the people were overweight in the south, higher than in the north $(32.0 \%)$ and the northeast $(30.9 \%) .^{14}$ There have been many studies which have found that overweight or obese people have higher prevalences of eating disorders than normal-weight people. ${ }^{15,16}$ In addition, this study found the median difference between current weight and target weight was $4 \mathrm{~kg}$, a significant difference.
This may be related to impressions young people have from social media, with their ideal body image of "Tyranny of Slenderness" which is now globally widespread. ${ }^{17}$ Concepts like this which become widely spread on social media could have effects on the students' attitudes and behaviors of eating, and especially on their concern about their current weight. This alone is a good explanation for the current high prevalence of eating disorders.

This study found the only factor significantly associated with eating attitudes and behaviors was BMI. Students who had a BMI defined as overweight (BMI $\left.23.00-24.99 \mathrm{~kg} / \mathrm{m}^{2}\right)$ or obese $\left(\geq 25.00 \mathrm{~kg} / \mathrm{m}^{2}\right)$ had significantly association with atypical eating attitudes and behaviors than normal BMI students $\left(18.50-22.99 \mathrm{~kg} / \mathrm{m}^{2}\right)$, with odds ratios of $3.3(95 \% \mathrm{Cl}=1.8-6.2)$ and $3.7(95 \% \mathrm{Cl}=$ 1.9-6.9), respectively. This finding is consistent to Chang's study $^{15}, 2015$ and Lipson's study ${ }^{16}, 2017$ which found overweight and obese participants had greater likelihoods of showing atypical eating attitudes and behaviors. Both of these studies also suggested that the reason for their findings was because modern social values advocate "thin for beauty". Furthermore, Myers and Rosen also reported that stigmatization is a common experience in overweight and obese people. Overweight people were frequently found to have low self-directedness and low persistence personality characteristics, which correlated with the process of developing obesity, and often engaged in strong efforts to cope with these stigmas, leading to atypical eating attitudes and behaviors. ${ }^{18} \mathrm{~A}$ study of the American Academy of Child and Adolescent Psychiatry found that obese people usually face job discrimination and social exploitation, leading to body dissatisfaction and atypical eating attitudes and behaviors. ${ }^{19}$ These studies may also help explain the strong associations between overweight and obesity BMls and atypical eating behaviors. 
There were no correlations between sex, faculty, targeted body weight, biological disease, psychological disease and current medication with atypical eating attitudes and behaviors. Both males and females showed concern about their shape, indicating "the gender-neutral nature of eating disorders". ${ }^{20}$ The common psychiatric disorders related to eating disorders are major depressive disorder, anxiety disorder, and bipolar disorder. ${ }^{15,21}$

Our study had several limitations. Firstly, due to the cross-sectional design, the results cannot conclusively show any causality of the factors associated with eating disorders. Secondly, this study was done during the summer holidays, so $60.0 \%$ of the participants were first and second year undergraduates, therefore our result might not be representative for the third year and fourth year undergraduates. Third, the Thai EAT-26 questionnaire only examines eating attitudes and behaviors, and cannot be used to suggest a definite diagnosis for eating disorders. Eating disorders must be diagnosed by a psychiatrist based on the fifth revision of the Diagnostic and Statistical Manual of Mental Disorders criteria.

\section{Conclusion}

Regarding the screening of PSU students with the EAT-26 (Thai version), $37.2 \%$ of the undergraduate students were found to have atypical attitudes towards their eating behaviors. We believe these findings were due to this study using a cut-off-point lower than other similar studies, and the present widespread use of online social media, through which there is extensive and rapid sharing of data and pictures about nutrition and atypical eating behaviors.

The overweight and obese BMI groups showed increasing risks of atypical eating attitudes and behaviors, compared to the normal weight group, due to the trend in the present rewarding and encouraging thinness for beauty and stigmatizing obesity, so obese people want to be thinner. Obese people have higher atypical eating attitudes and behaviors than normal.

We found no correlations between sex, faculty, targeted body weight, biological or psychological diseases or current medications and atypical eating attitudes and behaviors.

\section{Conflict of interest}

No potential conflict of interest relevant to this article was reported.

\section{References}

1. Hudson I, Hiripi E, Pope G, Kessler R. The prevalence and correlates of eating disorders in the National Comorbidity Survey Replication. Biol Psychiatry 2007;61:348-58.

2. Martin A, Volkmar FR. Lewis's child and adolescent psychiatry. a comprehensive textbook. $4^{\text {th }}$ ed. Philadelphia: Lippincott, Williams \& Wilkins; 2007;p.592-601.

3. Olden K, White L. Health-related disparities: influence of environmental factors. Med Clin North Am 2005;89:721-38.

4. Westmoreland P, Krantz MJ, Mehler PS. Medical complications of anorexia nervosa and bulimia. Am J Med 2016;129: 30-7.

5. Thomas JJ, Lee S, Becker AE. Updates in the epidemiology of eating disorders in Asia and the Pacific. Curr Opin Psychiatry 2016;29:354-62.

6. Mustelin L, Bulik CM, Kaprio J, Keski-Rahkonen A. Prevalence and correlates of binge eating disorder related features in the community. Appetite 2017;109:165-71.

7. Pitanupong J, Jatchavala C. Atypical eating attitudes and behaviors in Thai medical students. Siriraj Med J 2017;69:5-10.

8. Garner M, Garfinkel E. The Eating attitude test; an index of the symptoms of anorexia nervosa. Psychol Med 1979; 273-9.

9. Mintz L, Halloran M. The eating attitude test. Validation with DSM-IV eating disorder criteria. J Pers Assess 2000;74:489503.

10. Kaewpornsawan T, Pornjira Pariwatcharakul P, Pimratana W. Criterion validity study of Eating Attitudes Test-26 (EAT-26 Thai Version) among Thai females. HMJ 2013;58:283-96. 
11. Areemit R, Patjanasoontorn N. Anorexia nervosa in a Thai adolescent. Eat Weight Disord 2012;17: 207-9.

12. Pattanathaburt $P$, Somrongthong $R$, Thianthai $C$. Prevalence of disordered eating behaviors, body image dissatisfaction, and associated factors among Thai female undergraduate students. J Health Promot Educ 2013;51:151-60.

13. Winijjakul T. Social media and eating disorder [homepage on the Internet]. Bangkok: She Academe; 2016 [cited 2017 Nov 10]. Available from: http://sheacademy.in.th/?p=694

14. Health System Research Institute. Healthy survey in Tha population 2014 [monograph on the Internet]. Bangkok: Health System Research Institute; 2014 [cited 2017 Nov 20]. Available from: https://www.hsri.or.th/researcher/research/newrelease/detail/ $/ 7711$

15. Chang W, Nie M, Kang W, He P, Jin L, Yao S. Subclinical eating disorders in female medical students in Anhui, China: a cross-sectional study. Nutr Hosp 2015;31:1771-7.

16. Lipson K, Sonneville K. Eating disorder symptoms among undergraduate and graduate students at 12 U.S. colleges and universities. Eat Behav 2017;24:81-8.

17. Tyler M, Wilkinson A. The tyranny of corporate slenderness: 'corporate anorexia' as a metaphor for our age. Work Employ Soc 2007;21:537-49.

18. Myers A, Rosen JC. Obesity stigmatization and coping: relation to mental health symptoms, body image, and selfesteem. Int J Obes Relat Metab Disord 1999;23:221-30.

19. American Academy of Child and Adolescent Psychiatry. Obesity in children and teens [homepage on the Internet]. Washington: American Academy of Child and Adolescent Psychiatry; 2016 [cited 2017 Nov 10]. Available from: https:// www.aacap.org/aacap/families_and_youth/facts_for_ families/fff-guide/obesity-in-children-and-teens-079.aspx

20. National Eating Disorder Association. Males and eating disorder: research [homepage on the Internet]. New York: National Eating Disorder Association; 2012 [cited 2017 Aug 11]. Available from: https://www.nationaleatingdisorders.org/ sites/default/files/ResourceHandouts/ResearchonMales andEatingDisorders.pdf

21. Tseng MM, Chang $\mathrm{CH}$, Chen KY, Liao SC, Chen HC. Prevalence and correlates of bipolar disorders in patients with eating disorders. J Affect Disord 2016;190:599-606. 